\title{
Cross-species Amplification of Scallop Microsatellites in the Family Pectinidae
}

\author{
Min Hui ${ }^{1,2}$ \\ ${ }^{1}$ Institute of Oceanology, Chinese Academy of Sciences, Qingdao, China \\ ${ }^{2}$ Center for Ocean Mega-Science, Chinese Academy of Sciences, Qingdao, China
}

Email address:

minhui@qdio.ac.cn

\section{To cite this article:}

Min Hui. Cross-species Amplification of Scallop Microsatellites in the Family Pectinidae. Ecology and Evolutionary Biology.

Vol. 4, No. 4, 2019, pp. 55-59. doi: 10.11648/j.eeb.20190404.12

Received: September 3, 2019; Accepted: September 24, 2019; Published: November 7, 2019

\begin{abstract}
In the present study, 103 microsatellite markers were selected for cross-species amplification in four marine economic scallop species (Argopecten irradians, Chlamys farreri, Chlamys nobilis, and Mizuhopecten yessoensis) belonging to the family Pectinidae. As a result, in the 72 markers originated from C. farreri, 12 showed amplification products in C. nobilis, 12 in A. irradians and 11 in M. yessoensis. In the 12 markers developed from M. yessoensis, four markers could be amplified successfully in $A$. irradians, three in C. farreri, and one in C. nobilis. In the nine markers isolated from C. nobilis, two markers could be cross-amplified in A. irradians and one in M. yessoensis, but no marker was likely to be useful in C. farreri. In the nine markers of A. irradians, one marker was potentially workable for C. farreri, one in M. yessoensis, but none in C. nobilis. When the microsatellites were cross-species amplified, most of the PCR products showed low yield and ambiguous bands, while the numbers of alleles also decreased. Finally, three markers (CFMS016, CFCD131 and CFE04) were revealed to be successfully transferred among the four species providing candidate markers for ecological study of scallops, while most of the other markers were unique for one species with poor cross-species amplification, which might be useful for species identification.
\end{abstract}

Keywords: Cross-amplification, Genetic Marker, Scallop, Species Identification, Simple Sequence Repeats

\section{Introduction}

Scallops Argopecten irradians, Chlamys farreri, Chlamys nobilis and Mizuhopecten yessoensis are species belonging to the different genera of family Pectinidae, which are all important economic shellfish in China. Their living conditions are heterogenous, which determines their distribution areas. It is important for the ecologists to study the genetic diversity of the four species by molecular markers in order to protect the scallop resources.

Microsatellite DNA markers, with high polymorphism and codominance features, have been widely used in genetic analysis [1-5]. However, there are also many disadvantages caused by the costs involved in isolating, cloning, sequencing and characterizing microsatellite loci from the target species being examined for the first time. The discovery of microsatellite markers in related species provides an alternative approach to developing microsatellites in a simple and direct way. Transferabilities of microsatellite markers in related species have been studies in many shellfish, such as in
Crassostrea gigas [6] and Haliotis corrugata [7].

As for scallop, a large number of microsatellites have been developed for the four species [8-11]. In this paper, 103 microsatellite DNA marker's transferability was further evaluated in the four scallop species in order to develop potential markers for related species, especially to find markers that can be amplified in all four species to facilitate the ecology investigation and even to use them to evaluate the phylogenetic relationships of scallops.

\section{Materials and Methods}

\subsection{Sampling and DNA Extraction}

For transferability analysis, six individuals of each scallop species, A. irradians, C. farreri, C. nobilis and M. yessoensis were selected, which were popularly cultured in the seacoast of China. Among them, C. farreri and C. nobili were collected from the natural habitats in Changdao City (Shandong Province) and Dongshan City (Fujian Province) of China, 
respectively. The two introduced species, $M$. yessoensis and $A$. irradians, were collected from the Yantai City (Shandong Province). The live individuals were shipped to the laboratory, and the adductor muscles were taken and stored in the $-80^{\circ} \mathrm{C}$ refrigerator. Genomic DNA was extracted from adductor muscle using traditional phenol-chloroform method [12].

\subsection{Microsatellite Markers}

Among the 103 markers that were tested in cross-specific PCR amplifications, 72 markers came from $C$. farreri $[8,13,14], 12$ from M. yessoensis [9], nine from $C$. nobilis [10] and nine developed from $A$. irradiant [15]. The primer and microsatellites information could be found in the publications above.

\subsection{Cross-species Amplifications}

In order to ensure the amplification accuracy of these species-specific markers, the annealing temperature for transferability was adopted with a wide range: $40^{\circ} \mathrm{C}$ to $62^{\circ} \mathrm{C}$. PCR amplifications were set up in a $20 \mu \mathrm{L}$ volume composed of $100 \mathrm{ng}$ of genomic DNA (3 individuals mixed), $0.2 \mu \mathrm{M}$ of each primer, $200 \mu \mathrm{M}$ of each dNTP, 1 U Taq polymerase (Takara) and $1 \mathrm{x}$ universal PCR buffer. Thermal cycling was performed in a Biometra T-gradient Thermal Cycler System. The PCR program was used as following: $5 \mathrm{~min}$ at $95^{\circ} \mathrm{C}$ for initial denaturation; followed by 35 cycles of $30 \mathrm{sec}$ at $95^{\circ} \mathrm{C}$, $30 \mathrm{sec}$ at gradient temperature, $45 \mathrm{sec}$ at $72^{\circ} \mathrm{C}$ and a final extension at $72^{\circ} \mathrm{C}$ for $5 \mathrm{~min}$. PCR products were separated by electrophoresis on $10 \%$ non-denaturing polyacrylamide gel in $1 \mathrm{x}$ TBE buffer, and the gels were visualized by ethidium bromide staining. The amplification results were recorded.

The PCR product bands were classified into four types: (1) clear amplified (marked with optimized annealing temperature); (2) unorderly band; (3) weak band with few product; (4) No product.

\subsection{Polymorphism Evaluation of the Four Species Transferable Markers}

After recording, only the markers which could be amplified in all four species were selected to evaluate their allele numbers in six individuals of each species. The annealing temperature was re-optimized for them. The PCR amplification system was the same as above and the products were detected by $10 \%$ non-denaturing polyacrylamide gel as well and the results were written down by hand.

\section{Results}

\subsection{Cross Species Amplification}

In the 72 markers originated from C. farreri, PCRs of 11 markers yeilded clear amplification products in M. yessoensis, 12 in $C$. nobilis and 12 in A. irradians. In the 12 markers developed from $M$. yessoensis, three markers could be well amplified in $C$. farreri, one in $C$. nobilis and four in $A$. irradians. In the nine markers isolated from $C$. nobilis, no marker was likely to be useful in $C$. farreri, one in $M$. yessoensis, two in $A$. irradians, while among the nine markers isolated from $A$. irradians, one marker was potentially workable in $C$. farreri, one in $M$. yessoensis, but none in $C$. nobilis. Markers which were successfully amplified were given new annealing temperatures (Table 1). However, when amplified in related species, many of the PCR products showed low yield and ambiguous bands (Table 1).

Table 1. The cross-species amplification results in four scallop species.

\begin{tabular}{|c|c|c|c|c|c|}
\hline \multirow{2}{*}{ Loci } & \multicolumn{5}{|c|}{ Amplification results in four species } \\
\hline & C. farreri & M. yessoensis & C. nobilis & A. irradians & Transferbility in four species \\
\hline \multicolumn{6}{|l|}{ C. farreri loci } \\
\hline CFAD239 & + & - & W & $49.0^{\circ} \mathrm{C}$ & \\
\hline CFAD196 & + & M & $53.8^{\circ} \mathrm{C}$ & $\mathrm{M}$ & \\
\hline CFAD080 & + & W & W & M & \\
\hline CFAD139 & + & - & - & - & \\
\hline CFAD019 & + & - & - & - & \\
\hline AD195 & + & - & - & - & \\
\hline $13 \mathrm{RB} 01$ * & + & $45.5^{\circ} \mathrm{C}$ & $45.5^{\circ} \mathrm{C}$ & $45.5^{\circ} \mathrm{C}$ & $\sqrt{ }$ \\
\hline $15 \mathrm{RB} 04^{*}$ & + & $45.5^{\circ} \mathrm{C}$ & $\mathrm{M}$ & $45.5^{\circ} \mathrm{C}$ & \\
\hline $\mathrm{R}^{2} \mathrm{H} 4^{*}$ & + & $\mathrm{M}$ & $45.5^{\circ} \mathrm{C}$ & $61.0^{\circ} \mathrm{C}$ & \\
\hline 19RH06* & + & $45.5^{\circ} \mathrm{C}$ & W & M & \\
\hline 13RB04* & + & $\mathrm{M}$ & M & M & \\
\hline $22 \mathrm{FG} 07^{*}$ & + & W & W & $61.0^{\circ} \mathrm{C}$ & \\
\hline 20RB03* & + & - & - & - & \\
\hline CFAD099 & + & - & - & - & \\
\hline CFCD126 & + & W & $\mathrm{M}$ & $53.8^{\circ} \mathrm{C}$ & \\
\hline CFE26 & + & - & - & - & \\
\hline CFCD134 & + & W & $\mathrm{W}$ & $\mathrm{M}$ & \\
\hline CFE23 & + & - & - & - & \\
\hline CFE20 & + & $56.7^{\circ} \mathrm{C}$ & - & M & \\
\hline CFE19 & + & M & - & S & \\
\hline CFE15 & + & M & - & - & \\
\hline CFE18 & + & W & $50.5^{\circ} \mathrm{C}$ & M & \\
\hline CFE12 & + & $50.0^{\circ} \mathrm{C}$ & W & W & \\
\hline CFE11 & + & W & - & $\mathrm{S}$ & \\
\hline
\end{tabular}




\begin{tabular}{|c|c|c|c|c|c|}
\hline \multirow{2}{*}{ Loci } & \multicolumn{5}{|c|}{ Amplification results in four species } \\
\hline & C. farreri & M. yessoensis & C. nobilis & A. irradians & Transferbility in four species \\
\hline CFE07 & + & $58.6^{\circ} \mathrm{C}$ & $58.6^{\circ} \mathrm{C}$ & $\mathrm{W}$ & \\
\hline CFE04 & + & M & + & $\mathrm{S}$ & \\
\hline CFJD132 & + & $\mathrm{W}$ & M & M & \\
\hline CFKD007 & + & - & - & - & \\
\hline CFJD023 & + & M & $\mathrm{W}$ & $\mathrm{S}$ & \\
\hline CFKD113 & + & - & $47.0^{\circ} \mathrm{C}$ & $\mathrm{W}$ & \\
\hline CFLP83 & + & - & - & - & \\
\hline CFLP65 & + & - & $53.8^{\circ} \mathrm{C}$ & S & \\
\hline CFFD093 & + & $51.4^{\circ} \mathrm{C}$ & $51.4^{\circ} \mathrm{C}$ & - & \\
\hline CFWP7 & + & - & - & - & \\
\hline CFZB111 & + & - & - & $\mathrm{W}$ & \\
\hline CFZB27 & + & M & M & $56.7^{\circ} \mathrm{C}$ & \\
\hline CFZB07 & + & $\mathrm{W}$ & $\mathrm{W}$ & $46.7^{\circ} \mathrm{C}$ & \\
\hline CFFD144 & + & - & - & - & \\
\hline CFSSR001 & + & W & - & - & \\
\hline CFMSM019 & + & - & - & M & \\
\hline CFMSM009 & + & - & - & - & \\
\hline CFMSP003 & + & M & M & M & \\
\hline CFMSP075 & + & M & W & W & \\
\hline CFMSM016 & + & $54^{\circ} \mathrm{C}$ & $54^{\circ} \mathrm{C}$ & $54^{\circ} \mathrm{C}$ & $\sqrt{ }$ \\
\hline CFMSM020 & + & $49^{\circ} \mathrm{C}$ & $49^{\circ} \mathrm{C}$ & $49^{\circ} \mathrm{C}$ & $\sqrt{ }$ \\
\hline CFMSP007 & + & M & $\mathrm{W}$ & M & \\
\hline CFMSM014 & + & W & - & M & \\
\hline CFMSM018 & + & W & W & W & \\
\hline CFAD243 & + & - & W & - & \\
\hline CFAD245 & + & - & M & M & \\
\hline CFBD119 & + & + & + & - & \\
\hline CFCD103 & + & + & - & $\mathrm{W}$ & \\
\hline CFAD157 & + & - & - & - & \\
\hline CFAD183 & + & - & - & - & \\
\hline CFAD068 & + & - & - & - & \\
\hline CFDD097 & + & - & - & - & \\
\hline CFAD259 & + & - & - & - & \\
\hline CFCD131 & + & $54.0^{\circ} \mathrm{C}$ & $54^{\circ} \mathrm{C}$ & $54^{\circ} \mathrm{C}$ & $\sqrt{ }$ \\
\hline CFGD046 & + & $45.0^{\circ} \mathrm{C}$ & $45.0^{\circ} \mathrm{C}$ & $45^{\circ} \mathrm{C}$ & $\sqrt{ }$ \\
\hline CFLP072 & + & - & - & - & \\
\hline CFLD063 & + & - & - & - & \\
\hline CFLD009 & + & - & - & - & \\
\hline CFFD158 & + & - & - & - & \\
\hline CFML06 & + & - & - & - & \\
\hline CFMD016 & + & - & - & - & \\
\hline CFMD013 & + & - & - & - & \\
\hline CFOD082 & + & - & - & - & \\
\hline CFFD172 & + & - & - & - & \\
\hline CFBD022 & + & W & M & M & \\
\hline CFBD204 & + & - & - & - & \\
\hline CFLD144 & + & - & - & - & \\
\hline CFAD006 & + & - & - & - & \\
\hline Total & 72 & 11 & 12 & 12 & \\
\hline \multicolumn{6}{|c|}{ M. yessoensis loci } \\
\hline XY106 & - & + & S & - & \\
\hline XY129 & - & + & - & $45.0^{\circ} \mathrm{C}$ & \\
\hline PYER010 & - & + & - & - & \\
\hline PYER011 & $49.0^{\circ} \mathrm{C}$ & + & - & - & \\
\hline PYER015 & - & + & W & - & \\
\hline PYER023 & - & + & - & - & \\
\hline PYER031 & - & + & $\mathrm{W}$ & $45.0^{\circ} \mathrm{C}$ & \\
\hline PYMSM005 & - & + & - & - & \\
\hline XY138 & - & + & - & - & \\
\hline XY105 & $50^{\circ} \mathrm{C}$ & + & $50.0^{\circ} \mathrm{C}$ & $50.0^{\circ} \mathrm{C}$ & \\
\hline XY111 & M & + & $\mathrm{M}$ & M & \\
\hline XY128 & $53.8^{\circ} \mathrm{C}$ & + & W & $49.0^{\circ} \mathrm{C}$ & \\
\hline \multirow{2}{*}{\multicolumn{6}{|c|}{ C. nobilis loci }} \\
\hline & & & & & \\
\hline CNER053 & W & W & + & $\mathrm{W}$ & \\
\hline CNER048 & - & W & + & - & \\
\hline
\end{tabular}




\begin{tabular}{|c|c|c|c|c|c|}
\hline \multirow{2}{*}{ Loci } & \multicolumn{5}{|c|}{ Amplification results in four species } \\
\hline & C. farreri & M. yessoensis & C. nobilis & A. irradians & Transferbility in four species \\
\hline CNER036 & W & W & + & - & \\
\hline CNER064 & M & M & + & - & \\
\hline CNER067 & - & M & + & - & \\
\hline CNER003 & - & - & + & - & \\
\hline CNER041 & - & - & + & - & \\
\hline CNER021 & W & $53.8^{\circ} \mathrm{C}$ & + & $53.8^{\circ} \mathrm{C}$ & \\
\hline CNER070 & M & $\mathrm{W}$ & + & $53.8^{\circ} \mathrm{C}$ & \\
\hline Total & 0 & 1 & 9 & 2 & \\
\hline \multicolumn{6}{|c|}{ A. irradians loci } \\
\hline AIMS023 & $51.4^{\circ} \mathrm{C}$ & - & - & + & \\
\hline AIMS026 & - & - & $\mathrm{W}$ & + & \\
\hline AIMS027 & M & M & $\mathrm{W}$ & + & \\
\hline AIMS028 & - & M & - & + & \\
\hline AIMS021 & M & - & - & + & \\
\hline AIMS021 & - & - & - & + & \\
\hline AIMS022 & W & $\mathrm{W}$ & W & + & \\
\hline AIMS025 & M & W & M & + & \\
\hline AIMS027 & M & $45.4^{\circ} \mathrm{C}$ & M & + & \\
\hline Total & 1 & 1 & 0 & 9 & \\
\hline
\end{tabular}

+ : amplified in the focal species; -: no product; M: unorderly bands; W: weak bands.

\subsection{Polymorphism Evaluation of the Four Species Transferable Markers}

Five markers (CFMSM016, CFMSM020, CFCD131, CFGD046 and CFE04) were found to be successfully transferred among the four species, while many were unique for one species which might be useful for species identification, such as CFAD019 only amplified in C. farreri. When the five marker's polymorphism in six individual of each species were detected, it was found that there were some individuals that can't be amplified in certain loci, which might be caused by null allele or other reasons. Only CFMSM016, CFCD131 and CFE04 could be amplified in all individuals. Their annealing temperature and allele numbers were listed below (Table 2).

Table 2. The polymorphism information of the three markers in four scallop species.

\begin{tabular}{lllll}
\hline Loci & & CFMSM016 & CFCD131 & CFE04 \\
\hline Annealing temperature & $54^{\circ} \mathrm{C}$ & $54^{\circ} \mathrm{C}$ & $47^{\circ} \mathrm{C}$ \\
& C. farreri & 3 & 3 & 4 \\
Allele & M. yessoensis & 2 & 2 & 2 \\
number & C. nobilis & 1 & 2 & 2 \\
& A. irradians & 1 & 1 & 2 \\
\hline
\end{tabular}

\section{Discussion}

As shown in the results, fewer than $14.3 \%$ microsatellite markers are likely to be useful for related scallop species. Only three markers can be amplified in all four species, revealing low transferability rate of microsatellites from the family Pectinidae. It is in agreement with the result observed previously [16], in which they test cross amplification of microsatellites originating from $A$. irradians EST database in the four species. Another study also proclaims poor cross-species amplification of microsatellite DNA loci cloned from the Pacific oyster, with $C$. gigas versus $C$. ariakensis
(36.0\%), and $C$. gigas versus $C$. virginica (12.8\%) [10]. A possible reason is that they have great genetic divergence and evolutionary time span. In addition, no amplification bias was found between the four scallop species.

However, PCR success may have been underestimated in non-focal species because of the optimization limitations in the experiments. Only limited PCR reactions and gels have been run for each primer set, and comparisons have been conducted mainly under the PCR conditions optimized for the focal species. Despite these factors, a clear signal of PCR decay has been observed. In addition, decline in the ability to amplify microsatellites from related species is paralleled by a decline in allelic diversity for those markers that do amplify (Table 2). However, we expect this research can benefit new microsatellites markers isolation in related species of scallop and be helpful for ecological investigation, phylogenetic study and even species identification of pectinids.

\section{Conclusions}

In this study, it revealed low transferability of microsatellites from scallops of the family Pectinidae. Three out of 103 microsatellite markers (CFMS016, CFCD131 and CFE04) were successfully amplified across four scallop species (A. irradians, C. farreri, C. nobilis, and M. yessoensis) and polymorphic. Most of the other markers showed poor cross-species amplification, among which certain markers were specific to one species. These markers are expected to supply valuable genetic sources for ecological investigation and species identification of scallops.

\section{Acknowledgements}

This work was supported by the National Key R\&D Program of China (No. 2018YFD0900804). 


\section{References}

[1] Zane, L., L. Bargellonil and T. Patarnello (2002). Strategies for microsatellite isolation: a review. Molecular Ecology 11, 1-16.

[2] Chen, N., X. Luo, F. Wu, C. Mi, W. You, M. Huang and C. Ke (2016). Genetic structure of different cultured populations of the Pacific abalone Haliotis discus hannai Ino inferred from microsatellite markers. Journal of Shellfish Research 35, 661667.

[3] Slabbert, R., A. E. Bester, and M. E. D'Amato (2017). Analyses of genetic diversity and parentage within a South African hatchery of the abalone Haliotis midae Linnaeus using microsatellite markers. Journal of Shellfish Research 28, 369375 .

[4] Xu, X., G. Wang, C. Zeng and S. Li (2018) Parentage determination of the mud crab Scylla paramamosain using microsatellite markers. Aquaculture Research 49, 217-221.

[5] Duran, S., M. Pascual, A. Estoup and X. Turon (2010). Strong population structure in the marine sponge Crambe crambe (poecilosclerida) as revealed by microsatellite markers. Molecular Ecology 13, 511-522.

[6] Hedgecock, D., G. Li, S. Hubert, K. Bucklin and V. Ribes (2004). Widespread null alleles and poor cross-species amplification of microsatellite DNA loci cloned from the Pacific Oyster, Crassostrea gigas. Journal of Shellfish Research 23, 379-385.

[7] Díaz-viloria, N., R. Pérez-enríquez, G. Fiore-amaral, R. S. Burton and P. Cruz (2008). Isolation and cross-amplification of microsatellites in pink abalone (Haliotis corrugata). Molecular Ecology Resources 8, 701-703.

[8] Zhan A., Z. Bao, X. Hu, S. Wang, W. Peng, M. Wang, J. Hu, C. Liang and Z. Yue (2008). Characterization of 95 novel microsatellite markers for Zhikong scallop (Chlamys farreri) using FIASCO-colony hybridization and EST database mining. Fisheries Science 74, 516-526.

[9] Sun C., A. Zhan, M. Hui, W. Lu, X. Hu, J. Hu and Z. Bao (2007). Characterization of novel microsatellite markers from the Yesso scallop Mizuhopecten yessoensis. Molecular Ecology Notes 7, 106-108.

[10] Hui M., Z. Bao, A. Zhan, X. Hu, W. Lu, D. Chang and J. Hu (2006). Ten polymorphic dinucleotide microsatellite markers of the noble scallop Chlamys nobilis. Molecular Ecology Notes $6,1033-1035$.

[11] Meng X, Wang X, Guo X, M. Chen, Y. Zhang, H. Wang, Y. Chang and X. Qiu (2011). Characterization of novel polymorphic microsatellite markers from the cDNA library of Japanese scallop Mizuhopecten yessoensis and cross-species amplification in bay scallop Argopecten irradians. Journal of Genetics 90, 62-65.

[12] Sambrook, J., E. F. Fritsch and T. Maniatis. Molecular Cloning: A Laboratory Manual, 2nd ed. New York: Cold Spring Harbor Laboratory Press, 1989.

[13] Zhan, A. B., Z. M. Bao, B. Yao, X. L. Wang, M. Hui and J. J. $\mathrm{Hu}$ (2006). Polymorphic microsatellite markers in the Zhikong scallop Chlamys farreri. Molecular Ecology Notes 6, 127-129.

[14] Zhan A., Z. Bao, X. Hu, M. Hui, M. Wang, W. Peng, H. Zhao and $\mathrm{J}$. $\mathrm{Hu}$ (2007). Isolation and characterization of 150 novel microsatellite markers for Zhikong scallop (Chlamys farreri). Molecular Ecology Notes 7, 1015-1022.

[15] Zhan A., J. Hu, X.. Wang, W. Lu, M. Hui and Z. Bao (2006). A panel of polymorphic EST-derived microsatellite loci for the bay scallop (Argopecten irradians). Journal of Molluscan Studies 72, 436-438.

[16] Zhan, A., Z. M. Bao, X. Wang and J. Hu (2005). Microsatellite markers derived from Bay Scallop Argopecten irradians expressed sequence tags. Fisheries Science 71, 1341-1346. 